\title{
Pesquisa qualitativa, cartografia e saúde: conexoes"
}

Sabrina Helena Ferigato ${ }^{1}$

Sérgio Resende Carvalho ${ }^{2}$

FERIGATO, S.H.; CARVALHO, S.R. Qualitative research, cartography and healthcare: connections. Interface - Comunic., Saude, Educ., v.15, n.38, p.663-75, jul./set. 2011.

In this literature review study, we sought to explore the frontiers between the production of healthcare knowledge, qualitative research and cartography. We started with a brief retrospective look at the historical construction of qualitative research in general, followed by presentation of cartographic investigation as a possible method for qualitative healthcare research. After presenting the conceptual basis of this method for knowledge production, we identified its potential and challenges with regard to developing research within the field of public health.

Keywords: Cartography. Qualitative research. Healthcare.
Trata-se de uma revisão bibliográfica para explorar as fronteiras entre a produção de conhecimento em saúde, as pesquisas qualitativas e a cartografia. Iniciamos com uma breve retrospectiva sobre a construção histórica das pesquisas qualitativas em geral, para,

posteriormente, apresentarmos a investigação cartográfica como método possível para as pesquisas qualitativas em saúde. Uma vez apresentados os aspectos conceituais desse modo de produção de conhecimento, identificamos suas potencialidades e desafios para o desenvolvimento das pesquisas no campo da Saúde Coletiva.

Palavras-chave: Cartografia. Pesquisa qualitativa. Saúde.

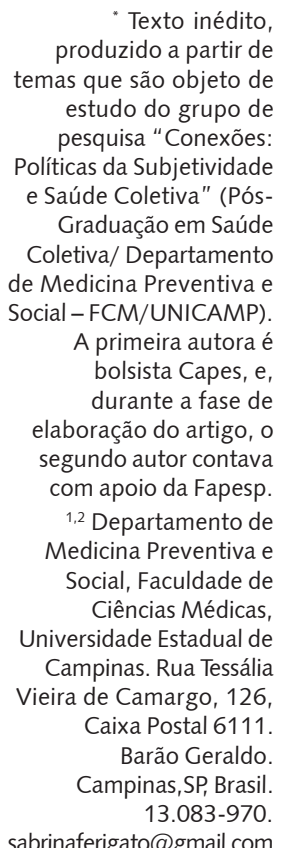

sabrinaferigato@gmail.com 


\section{Introdução}

Este trabalho se destina ao estudo da cartografia como método de pesquisa, em sua interface com as pesquisas qualitativas no campo da saúde - o que consiste em um importante exercício teórico para a atualidade mediante a constatação de que uma quantidade significativa da produção de conhecimento no campo da saúde pública resulta de pesquisas que adotam metodologias denominadas como qualitativas, sem que haja necessariamente uma reflexão sobre as possibilidades e limites de tais metodologias, bem como sobre as aproximações e distinções entre estas e outras propostas metodológicas.

Adotaremos, para este trabalho, o método de revisão bibliográfica. Essa revisão, dita de outra maneira, refere-se à leitura como gesto, como obra (Orlandi, 1996). Defrontamo-nos com um exercício de aproximações e confrontos com os textos, nos aprofundando e mergulhando nas linhas do nosso interesse - produção-criação-re-criação no ato de ler e escrever. Como diriam Deleuze e Guattari (1995), trata-se de uma abordagem rizomática dos textos, que os coloca em diálogo, em acoplamento, para a criação de novas leituras.

Com essa abordagem, buscaremos, primeiramente, refletir sobre as metodologias de caráter qualitativo e, na sequência, explorar as possibilidades abertas pela cartografia para esse campo, com especial interesse para a produção de conhecimento em saúde.

\section{A pesquisa qualitativa}

Até o início do século $X X$, as metodologias de pesquisas qualitativas emergem num contexto científico marcado pela proximidade com os interesses das políticas hegemônicas e pela abordagem positivista, que condicionava seus conceitos, métodos e técnicas. Neste contexto, é dada ênfase a essa nova metodologia, com o intuito de responder às questões que emergiam do processo de pesquisar, para as quais os métodos quantitativos tradicionais mostravam-se insuficientes.

De acordo com Denzin e Lincoln (2005), a palavra qualitativa implica uma ênfase sobre as qualidades das entidades, sobre os processos e os significados que não são examinados ou medidos experimentalmente em termos de quantidade, quantia, intensidade ou frequência. Ele ressalta que a competência da pesquisa qualitativa é o mundo da experiência vivida.

A etnografia proposta pela Antropologia Social, a partir da vivência direta do pesquisador na realidade onde o objeto está inserido, marca o pioneirismo das metodologias qualitativas de pesquisa, em especial a partir dos estudos de Malinowski desenvolvidos na década de 1920. Formas de abordagem como essa vêm apresentando significativo avanço nos últimos anos. Esse avanço não se situa apenas na produção de metodologias alternativas aos tradicionais métodos quantitativos, mas carrega a marca de um redimensionamento do encontro que se dá no ato de pesquisar, entre pesquisador e objeto de pesquisa.

Radcliffe-Brown, Margaret Mead, Gregory Bateson e Malinowski são alguns dos "etnógrafos solitários" que estão na origem da etnografia clássica, que vai de 1900 a 1945 (Denzin, Lincoln, 2005). Nesse período, os pesquisadores qualitativos escreveram trabalhos retratando com 'objetividade' a sua experiência de campo. No centro de suas preocupações, identificamos a tentativa de oferecer uma interpretação válida, confiável e objetiva dos fatos observados.

Após a década de 1950, o conjunto de trabalhos que caracterizam a fase moderna da investigação qualitativa é marcado pela tentativa de construção de estudos qualitativos de processos sociais, entre os quais, aqueles que faziam referência a condutas desviantes e ao controle social nas escolas e na sociedade em geral. Denzin e Lincoln (2005) consideram o trabalho de Becker et al. (1961) - Boys in White - como um marco desse período.

Caracteriza essa investigação, a construção de uma metodologia qualitativa que buscava ser "tão rigorosa" quanto a pesquisa quantitativa, por meio da combinação de observação participante, entrevistas abertas e uma análise cuidadosa dos materiais por intermédio da ampla utilização de critérios estatísticos.

Muitas destas características e posicionamentos seguem presentes, constituindo uma porta de entrada para o campo para muitos iniciantes da pesquisa qualitativa. 
Constatações como esta sustentam, em parte, a afirmação de que

\begin{abstract}
infelizmente, pesquisa qualitativa, em muitos formatos (observação, participação, entrevista, etnografia), serve como uma metáfora para o conhecimento, o poder e a verdade colonial. A metáfora funciona desta maneira. Pesquisa - quantitativa e qualitativa - é ciência. A pesquisa nos dá o fundamental para o informe e a representação do "outro". No contexto colonial, a pesquisa se torna um caminho objetivo de representar o outro de pele escura para o mundo branco. (Denzin, Lincoln 2005, p.1)
\end{abstract}

Essa citação nos alerta para o fato de que a simples afirmação do adjetivo "qualitativo" não nos garante o compromisso com valores como justiça e a equidade uma vez que muitas formulações desta modalidade de investigação podem seguir comprometidas com uma maneira de conhecer, entender e controlar o "outro", considerado como exótico, estrangeiro, desviante ou problemático (Vidich, Liman apud Denzin, Lincoln, 2005).

Nas décadas que se seguiram até os dias de hoje, vem ocorrendo uma complexificação crescente do campo das metodologias qualitativas, que passam a ser empregadas em outras disciplinas científicas sociais e comportamentais, incluindo: a Educação (especialmente o trabalho de Dewey), a História, as Ciências Políticas, a Medicina, a Enfermagem, o Trabalho Social, e a Comunicação (Denzin, Lincoln, 2005).

Além da ampliação da variedade das disciplinas que vieram a incorporar as investigações qualitativas, amplia-se também a diversidade de metodologias e correntes teóricas alternativas ao positivismo, que passam a ser utilizadas como referência para os pesquisadores qualitativistas.

Entre essas correntes, podemos citar: a tradição britânica, as tradições pragmáticas, naturalistas e interpretativas americanas, as perspectivas estruturais e pós-estruturais (marxistas semióticas, hermenêuticas, fenomenológicas), além dos estudos feministas, os estudos latinos e afro-americanos, entre outros (Denzin, Lincoln 2005). Essas linhas tradicionais mostram, por si só, que é um erro pensar que todos os pesquisadores qualitativistas têm as mesmas visões em relação ao modo de pesquisar ou ao ethos do pesquisador. Para Denzin e Lincoln (2005), as diferenças positivistas, pós-positivistas e pósestruturais definem os diferentes discursos construídos no universo das pesquisas qualitativas.

Para esses autores, os positivistas defendem a ideia de que a realidade a ser estudada é passível de ser apreendida em relatos objetivos, num sistema de representações de verdade. Já para os pós-positivistas, é possível produzir relatos apenas parcialmente objetivos do objeto em questão, pois o mesmo pode ser abordado por uma variedade grande de métodos, sempre imperfeitos.

Neste trabalho, daremos maior enfoque à perspectiva pós-estruturalista, que referencia o método de pesquisa no qual iremos nos aprofundar posteriormente - a cartografia. Para os pós-estruturalistas, é impossível captar totalmente o significado de uma ação, de um texto ou de um objeto, pois a linguagem é entendida como um sistema instável de referentes (Denzin, Lincoln, 2005).

Com base nessa pequena retrospectiva, entendemos que a pesquisa qualitativa significa diferentes coisas em distintos momentos. Mas, embora traçando diferentes abordagens teóricas, todo trabalho de pesquisa que se define como qualitativo deve levar em conta a complexidade histórica do campo, o contexto do objeto pesquisado e a experiência vivida.

Investigadores qualitativos tencionam a natureza socialmente construída da realidade, a relação íntima entre o pesquisador e o que é estudado, e os constrangimentos situacionais que formatam a pesquisa. Tais pesquisadores enfatizam a natureza intrinsecamente valorativa da pesquisa. (Denzin, Lincoln, 2005, p.10)

Investigação qualitativa é, portanto, uma atividade que se afirma a partir do contexto situacional, da localização e implicação do observador em relação ao objeto e seu entorno. Esta mudança paradigmática marca uma tendência dessa forma de abordagem rumo a um compromisso com a mudança.

Para Denzin e Lincoln (2005), isso se refere a um conjunto de práticas materiais (como notas de campo, entrevistas, conversações, fotografias, narrativas e memórias de si) que possibilitam tornar o mundo visível e transformá-lo a partir do ato de pesquisar. 
Desta forma, o pesquisador procura utilizar um amplo arcabouço de métodos de pesquisa buscando melhor entender o foco de atenção de seu estudo. É sempre bom lembrar que, neste contexto, cada prática torna o mundo visível de diferentes maneiras. Dentro das múltiplas possibilidades que se abrem com as metodologias qualitativas, buscaremos discutir certo modo de trazer o mundo ao campo das visibilidades e dos enunciados - a investigação cartográfica.

Para isso, é importante esclarecer, mais uma vez, que este trabalho constitui um exercício de traçar aproximações possíveis entre a pesquisa qualitativa e a cartografia, e não de "enquadrar" as práticas cartográficas no campo exclusivamente qualitativo da produção de conhecimento.

Embora não seja objeto deste estudo realizar análises comparativas entre pesquisas quantitativas e qualitativas, cabe ressaltar que a cartografia também pode fazer uso de uma multiplicidade de abordagens não apenas qualitativas. Ou seja, pesquisas quantitativas e qualitativas podem constituir práticas cartográficas. Nosso esforço será o de identificar zonas de comunidade e de distinguibilidade entre a cartografia e as pesquisas qualitativas em geral que merecem ser destacadas.

Por exemplo, as práticas interpretativas da realidade que são centrais no universo de muitas metodologias qualitativas - como a hermenêutica, por exemplo - não têm centralidade na cartografia. Para os cartógrafos, pesquisar não é necessariamente interpretar o mundo, nem compreender a realidade, trata-se de produzir o mundo, construir realidades. Além disso, alguns formatos de pesquisas qualitativas também podem dar destaque à linha representacional, da qual os cartógrafos buscam enfaticamente escapar (Passos, Kastrup, Escóssia, 2009).

No entanto existem importantes zonas de comunidade entre as pesquisas qualitativas e a cartografia, especialmente no que se refere a pesquisar e acompanhar processos, a experiência de produzir conhecimento no mundo da experiência vivida. Pesquisar, intervir, transformar - vamos mergulhar nos desafios do cartógrafo.

\section{A cartografia como método de pesquisa-intervenção}

A formulação que discutiremos coloca em questão a cumplicidade com as formas instituídas de verdade, bem como as estruturas e rituais que sustentam parte da vida em sociedade. Repensa a tradição de pesquisa e seus de conceitos, como validade, confiabilidade e objetividade. Coloca em questão também a diferença entre o escrever e o trabalho de campo, afirmando o papel de validação da escrita na investigação (Richardson, Pierre, 2005; Richardson, 2000). A escrita, assim como na etnografia, é aqui assumida como um método da investigação que se produz a partir de sucessivos movimentos de autorreflexão.

Assume-se, aqui, a existência de uma crise de representação da pesquisa qualitativa, na qual se afirma que a experiência social é criada no texto escrito pelo pesquisador na tentativa de capturar a experiência.

Para Passos, Kastrup e Escóssia (2009), a pesquisa qualitativa enfrenta alguns impasses metodológicos atribuídos à natureza subjetiva de grande parte de suas investigações, especialmente quando essa prática se faz a partir do encontro de sujeitos e pelo que se expressa neste encontro, como são as práticas em saúde. Por isso, investigações dessa natureza pedem estratégias metodológicas e procedimentos investigativos mais abertos e inventivos.

Ao darmos ênfase aos processos de produção de subjetividade como eixo de destaque nas ações em saúde e, também, na produção de saber, nos aproximamos da cartografia. Embora saibamos que não são apenas as práticas cartográficas que se propõem a valorizar a subjetividade no campo da pesquisa, escolhemos essa abordagem pela afinidade que temos em relação ao entendimento que seus teóricos apresentam sobre o sujeito e sobre a produção de subjetividade, pautados na Filosofia da Diferença.

Com o conceito de produção, entende-se que é a partir de uma história tecnológica dos modos de compreensão e de experiência contínua do eu que autores como Foucault nos informam sobre o sujeito. Deste modo, a subjetividade deixa de estar ligada apenas aos domínios da representação, da interioridade e passa a ligar-se visceralmente aos conjuntos sociais (Paiva, 2000). Por sua vez, o sujeito não constitui um universal, mas o produto contingente de diagramas de força e de produção de subjetividades que o atravessam. 
Os Filósofos da Diferença - representados por autores como Espinosa, Niestzche, Deleuze, Guattari, Foucault, Bergson, entre outros - ofereceram um novo conjunto de conceitos para se pensarem as mudanças nas formas de ser e conhecer na atualidade. Com essa inspiração, investigadores como Maturana e Varela (1995), entre outros, têm estimulado a continuidade dessas produções na atualidade, incluindo a aproximação desse pensamento com teorias como a análise institucional e a teoria crítico-social.

Estas vertentes têm sustentado uma proposição que no Brasil vem sendo denominada "investigação cartográfica". Entre destacados estudiosos brasileiros desta vertente, citamos, no campo da psicologia, autores como: Rolnik (2007); Do Eirado (2005), Fonseca (2007), Passos, Kastrup e Escóssia (2009), Benevides de Barros (2007), entre outros. Na Saúde Coletiva, esta vertente se faz presente na produção de: Merhy (2002), Teixeira (2003), Franco et al. (2009), Ceccim e Feuerwerker (2004), Carvalho, Ferigato e Barros (2009) etc.

A ideia da cartografia como uma prática do conhecer foi expressivamente trabalhada pelo filósofo francês Gilles Deleuze

\begin{abstract}
que se apropria de uma palavra do campo da Geografia - Cartografia - para referir-se ao traçado de mapas processuais de um território existencial. Um território desse tipo é coletivo, porque é relacional; é político, porque envolve interações entre forças; tem a ver com uma ética, porque parte de um conjunto de critérios e referências para existir; e tem a ver com uma estética, porque é através dela que se dá forma a esse conjunto, constituindo um modo de expressão para as relações, uma maneira de dar forma ao próprio território existencial. Por isso, pode-se dizer que a cartografia é um estudo das relações de forças que compõem um campo específico de experiências. (Farina, 2008, p.9)
\end{abstract}

De acordo com Deleuze e Guattari (1995), a cartografia é útil para descrever processos mais do que estados de coisa. Saliente-se o termo processo e a possibilidade de a cartografia contribuir para as pesquisas qualitativas que se propõem ao acompanhamento de processualidades, visto que o método qualitativo pode ser caracterizado como "aquele que quer entender como o objeto de estudo acontece ou se manifesta; e não aquele que almeja o produto, isto é, os resultados finais matematicamente trabalhados" (Turato, 2005, p.509).

Isso nos indica um procedimento de análise a partir do qual a realidade a ser estudada está em constante transformação e movimento, uma realidade composta por diferentes narrativas, contextos e linhas de força a serem consideradas em sua complexidade e singularidade. A transformação da realidade, aqui referida, também ocorre a partir do próprio observador e das interferências da pesquisa no universo real, o que implica o pesquisador com o campo problemático na transformação de si, do objeto e de seu contexto, conferindo ao trabalho da pesquisa seu caráter intrínseco de intervenção, como já nos indicava Lourau (2004).

Segundo Kastrup (2008), a noção de pesquisa-intervenção oriunda do movimento da Análise Institucional afirma o ato político de toda investigação e se embasa em uma crítica direta à política de pesquisa ortodoxa, que defende a eliminação da participação do pesquisador na produção de conhecimento objetivo e a suposta neutralidade da pesquisa. Essa nova reconfiguração do modo de se produzir conhecimento alia-se ao conceito de cognição como criação, como autopoiese, conforme proposto por Maturana e Varela (1995). Subjetividade e Objetividade não são tomadas como fundamentos da cognição, mas como efeitos desse processo. Tal concepção encontra suas raízes no construtivismo de Piaget (1978). Por este caminho, a noção de coengendramento do sujeito e do objeto indica a crítica do modelo da representação. Sujeito e objeto são coemergentes do processo de pesquisar, são efeitos, e não condição da atividade cognitiva.

Neste sentido, Passos, Kastrup e Escóssia (2009) identificam, no mínimo, três inversões do modo de condução da pesquisa. Primeiro, o pesquisador deixa de se orientar pelo que se sabe de antemão sobre determinada realidade (know what), e passa a orientar-se pelo modo de se fazer pesquisa (know how); em segundo lugar, direciona-se o trabalho da pesquisa do saber-fazer para o fazer-saber. A terceira reversão se contrapõe a uma tradição que define o método a partir das metas, propondo, em seu lugar, 
a centralidade do caminho (hódos) em relação a metas (metá). O que se propõe é a efetivação de um Hódos-metá no lugar de um método. Fazer a afirmação do primado do caminho, e não da meta, faz com que a pesquisa seja, antes de tudo, uma experimentação, um processo em aberto em que operam séries de dobras e desdobras, de inesgotáveis problemas e descobertas.

Referimo-nos a uma aposta na experimentação do pensamento e no imprevisível próprio dos processos de produção de subjetividade. Esse movimento torna o método de pesquisa mais próximo do objeto e mais congruente com os movimentos da vida e com as ações em saúde.

Tomando em conta o caráter de processualidade relevante a esse método e sua dimensão interventiva, para Kastrup e Barros (2009), a cartografia produz efeitos de transformação da realidade, que também devem ser analisados, como já mencionado anteriormente.

Deste modo, estamos nos referindo a um modo de pesquisar que se propõe a pesquisar processos, que serão produzidos e, ao mesmo tempo, transformados pelo próprio ato de pesquisar em agenciamento com as linhas de força e de subjetivação do campo problemático. Como estudar esse movimento processual de produção de subjetividade?

Instigados a mergulhar nesse desafio, Passos, Kastrup e Escócia (2009) organizaram um livro intitulado "Pistas do método da cartografia: Pesquisa intervenção e produção de subjetividade", que exprime um importante avanço para as pesquisas cartográficas brasileiras. Nessa obra, são apontadas "pistas" para a construção desse modo de pesquisar. Para eles, a cartografia como direção metodológica deve ser articulada com oito ideias que compõem um plano de ação ou de pesquisa:

A pista (1) elaborada por Passos e Barros (2009a) indica que toda pesquisa é intervenção e que toda intervenção em saúde é sempre uma atitude clínico-política. Apoiados nos referenciais da Análise Institucional e na contribuição metodológica de Félix Guattari, defendem a ideia de que o campo de análise não se separa do campo de intervenção. Segundo tal abordagem, conhecer não é representar uma realidade preexistente, mas é um processo de invenção de si e do mundo (Kastrup, 1999; Maturana, Varela, 1995). Sujeito e objeto não são polos prévios ao processo de conhecer, mas são engendrados pelas próprias ações cognitivas de modo recíproco e indissociável. Ocorre, aqui, uma indissociabilidade entre a produção de conhecimento e a transformação da realidade.

Na pista (2), adotando uma política construtivista, Kastrup (2009) define os quatro gestos da atenção cartográfica durante o trabalho de campo: o rastreio, o toque, o pouso e o reconhecimento atento gestos propícios para acessar elementos processuais provenientes do território, de interesse do cartógrafo. Para inibir a atenção seletiva que habitualmente domina nosso funcionamento cognitivo, esse funcionamento atencional requer uma concentração sem focalização, por meio da ideia de uma atenção à espreita, ao mesmo tempo flutuante, concentrada e aberta, conforme Deleuze indica em seu Abécédaire.

A terceira pista discute a ideia, já apontada neste texto, de que "cartografar é acompanhar processos"; processos em seu caráter de processualidade, que também estão presentes em cada momento da pesquisa. Pozzana e Kastrup (2009) afirmam que a cartografia não se destina a isolar o objeto de suas articulações históricas e de suas conexões com o mundo. Para isso, é preciso dar conta de suas modulações e de seus movimentos permanentes, "dar língua para afetos que pedem passagem" (Rolnik, 2007, p.23). Esse acompanhamento exige a produção coletiva do conhecimento (há um coletivo se fazendo com a pesquisa) e depende de uma atitude, de um ethos do pesquisador imerso no plano das intensidades de um território.

A pista (4), proposta por Kastrup e Barros (2009), apresenta os movimentos-funções do dispositivo no método da cartografia. As autoras defendem que a cartografia enquanto método de pesquisa requer procedimentos concretos encarnados em dispositivos. Na concepção de Deleuze (1990), os dispositivos são máquinas que fazem ver e falar, compostas por linhas de força, de visibilidade, de enunciação e de subjetivação. O que caracteriza um dispositivo na pesquisa cartográfica é sua irrupção naquilo que se encontra bloqueado para a criação.

A quinta pista, formulada por Escóssia e Tedesco (2009), aponta que, ao lado das formas e dos objetos com seus contornos estáveis, existe um plano coletivo de forças que os produz, um plano movente da realidade das coisas que não pode ser abandonado quando se pretende compreender um objeto. A cartografia aqui é apontada como estratégia de acesso, de análise e de construção desse plano. 
A sexta pista, desenvolvida neste livro por Passos e Do Eirado (2009), aponta para a ideia de dissolução do ponto de vista do observador. A cartografia requer a suspensão da posição pessoal do pesquisador, marcada por interesses, expectativas e saberes anteriores, de modo que, no encontro entre pesquisador e o objeto da pesquisa, o primeiro possa colocar-se de forma efetivamente presente, ou seja, não perceber através do crivo de juízos prévios ou pré-conceitos (Kastrup, 2008). O texto revela uma recusa do objetivismo científico e, ao mesmo tempo, do subjetivismo, que apresentados a partir de posicionamentos diferentes são duas faces da mesma moeda.

A pista (7) discursa sobre a importância da imersão do cartógrafo no território pesquisado. Partindo do conceito de território existencial proposto por Deleuze e Guattari em Mil Platôs - em que é a expressividade, e não a funcionalidade, que explica a formação territorial -, Alvarez e Passos (2009) defendem que a pesquisa cartográfica sempre pressupõe a habitação de um território, numa postura de receptividade afetiva, encarnada nas situações reais, o que permite ao observador falar "com", e não apenas falar "sobre" um objeto.

A oitava pista nos oferece indicações sobre a escrita dos textos cartográficos. Passos e Barros (2009b) apresentam a ideia de que esse método exige uma mudança nas práticas habituais de narrar uma pesquisa, num esforço para uma análise expressiva do discurso, em busca de uma "política da narratividade" - um modo de dizer que expresse processos de mudança de si e do mundo.

Entendemos, de acordo com os autores, que as práticas clínicas e de pesquisa qualitativas sempre dizem respeito a narrativas. As diferentes formas de terapêutica e de produção de dados (entrevistas, grupos focais, observação participante, pesquisa bibliográfica...) indicam diferentes maneiras de narrar, associadas a um direcionamento político que escolhemos.

Se falamos de uma escrita que valoriza a narrativa dos sujeitos de pesquisa, falamos, ao mesmo tempo, de uma forma de pesquisar que valoriza o sujeito. Tomar os sujeitos e o encontro entre eles como objeto de investigação-intervenção é o que fazemos nas pesquisas qualitativas em Saúde.

\section{As pesquisas qualitativas em Saúde no Brasil: potencialidades e desafios do método cartográfico}

Durante a maior parte da história das pesquisas em saúde, os modelos biomédicos e quantitativistas eram tidos como referenciais hegemônicos de investigação. No entanto, nas últimas décadas, mediante a incorporação de determinantes culturais, econômicos, históricos e psicossociais no entendimento do processo saúde-doença-intervenção, fez-se necessária a incorporação de procedimentos mais abertos, de metodologias qualitativas ou quantiqualitativas no universo da produção de conhecimento. Essa incorporação reconhece as múltiplas maneiras de expressão da realidade, o que exige uma multiplicidade não excludente de formas de abordagem do objeto ou de metodologias de pesquisa.

Gil et al. (2006) apresentam algumas situações de investigação em saúde, nas quais são potentes os usos de pesquisas qualitativas, entre elas, podemos citar: a) situações em que se pretendem explicar fenômenos que ocorrem em situações muito complexas ou singulares (como os estudos de caso, por exemplo); b) situações em que o pesquisador tem uma percepção acerca do papel da Ciência e da produção do conhecimento voltadas para a compreensão do cotidiano e para as transformações sociais das práticas do cuidado (como, por exemplo, as pesquisas formalmente interventivas); c) situações de pesquisas exploratórias, nas quais não se imagina chegar a uma resposta definitiva para o problema (levando em consideração a flexibilidade e particularidade da metodologia).

O desafio de acompanhar, pesquisar e avaliar os encontros e desencontros entre sujeitos produzidos pelos cuidados em saúde parece ser o elemento que aproxima e, por que não dizer, apaixona boa parte dos estudiosos em pesquisa qualitativa no Brasil, onde se dá especial destaque à participação dos distintos sujeitos que estão envolvidos nas ações em saúde, no processo de avaliação e pesquisa, sendo incorporadas suas demandas, valores, sentidos, desejos e conflitos que se fazem presentes no ato de pesquisar. Esta forma de desenvolvimento de pesquisa pode ser verificada, também, nos estudos denominados como pesquisa-ação e pesquisa intervenção.

No que tange à produção do conhecimento interventivo em saúde, gostaríamos de explorar, dentro do amplo escopo das pesquisas qualitativas, um conjunto de trabalhos cartográficos que vêm se 
dedicando a pesquisar e avaliar experiências de mudanças na atenção e gestão do Sistema Único de Saúde a partir de uma leitura crítica dos filósofos da diferença e da articulação entre as metodologias qualitativas e a cartografia.

No Brasil, mais do que uma escolha intelectual, esta vertente vem se impondo como uma possibilidade de criação de estratégias, arranjos e dispositivos junto aos serviços e práticas de atenção no SUS e para o desenvolvimento de pesquisas em saúde.

$\mathrm{Na}$ centralidade destas formulações, encontra-se uma leitura singular sobre estratégias de produção do conhecimento, na qual o processo de saúde-doença-intervenção se refere à complexa configuração das formas de funcionamento do subjetivo, que se constitui no agenciamento entre: usuários e profissionais de saúde, instituições, procedimentos clínicos, diagnósticos, territórios etc.

Para uma pesquisa cartográfica, o que interessa no estudo desses agenciamentos são: as relações de força e as forças liberadas nessas relações (política), os enunciados que regem essas forças e as colocam em funcionamento, os valores produzidos a partir delas, que permitem ao sujeito relacionar-se consigo mesmo e com os outros (ética) (Farina, 2008).

Além disso, é importante ressaltar que as instituições de saúde, atravessadas por todas essas questões e enunciados, se movimentam para sustentar ou resistir a seus determinantes externos e internos, vivem numa processualidade de reinvenção e repetição constante na qual a cartografia busca intervir.

Os encontros de diferentes linhas de força e de criação (as práticas clínicas, os núcleos profissionais, as tecnologias, a ciência, a política, o saber e a formação em saúde) têm gerado múltiplos desdobramentos: novos arranjos institucionais para novos campos de ação, novas doenças, novos dispositivos de intervenção, novos discursos. Conceitos como o de acolhimento (Teixeira, 2003), linhas de cuidado (Franco, Magalhães Jr., 2003), e arranjos como o apoio matricial e a equipe de referência (Campos, 2005) são exemplos desses desdobramentos na Saúde Coletiva. Ao mesmo tempo em que percebemos inovações como estas, verificamos repetições e variações das antigas formas profissionais e seus campos.

Cartografar esses processos na Saúde Coletiva é investigar o que dá expressão e o que transforma os modos de produção de cuidado; escutar os seus "ruídos", seus incômodos; fazer aparecer as coisas que estão ali, mas não têm visibilidade (Franco, Merhy, 2009).

Saúde, doença e intervenção, praticadas pela economia do contemporâneo, produzem prescrições, sintomas, mortes, tratamentos e curas, mas também uma sensibilidade específica aos modos de produção de vida ou de adoecimento, aos modos de produção coletiva de novas subjetividades. Subjetividade que se dá no contato, na comunicação, no encontro, onde se lançam dispositivos que operam como redes de interfaces (Teixeira 2001).

Atendimentos individuais, processos grupais, visitas domiciliares, acolhimento, quando olhados sob essa perspectiva, funcionam como dispositivos que interconectam diferentes encontros, diferentes espaços coletivos de conversa (Teixeira, 2003), o que remete aos diferentes territórios investigados na produção de cuidado (Eichelberger, 2009).

Guattari (1985) diferencia espaço de território. Espaço de funções planejadas, projetadas, programadas, e território enquanto espacialidade materializada, definida a partir de relações subjetivas os denominados "territórios de subjetivação ou territórios existenciais" (Guattari, 1985, p.114).

Assim, na perspectiva cartográfica, investigar um território de produção de saúde é buscar captar suas dinâmicas, seus movimentos, seus acontecimentos, o que se passa no entre instituição-território, instituído-instituinte. Um lugar que se propõe a ser um Espaço do Acontecer (Santos, 2005), um território compartilhado que se oferece a um papel analítico.

Para elucidar essa teorização, citaremos um exemplo prático, proposto por Franco e Merhy (2009): Numa pesquisa qualitativa tradicional sobre um estabelecimento de saúde específico, busca-se conhecê-lo a partir da sua estrutura organizacional (organograma, fluxos estruturados, Recursos humanos...), ou seja, pela ótica do mundo racionalmente concebido. Pela perspectiva cartográfica, se propõe uma análise a partir de outros campos de visibilidade, abrindo a percepção desse estabelecimento de saúde sob outro ângulo: analisar seus funcionamentos e o que eles produzem. Nesta linha, pode-se perceber a existência de várias unidades de saúde em uma mesma. 
Essa forma de se colocar como pesquisador, parte da concepção de que toda prática de saúde opera no campo dos processos de subjetivação, que a produção de cuidados opera por fluxos de intensidade e afetos que circulam entre usuários, trabalhadores e gestores envolvidos no processo saúde-doençaintervenção.

Também podemos citar, como exemplo ilustrativo dessa forma de abordagem, o estudo de Pacheco e Carvalho (2009) que, ao pesquisarem a relação entre a Clínica e a Prevenção, buscaram revelar o que há entre, o que há na borda destas duas esferas de cuidado, ou seja, pensar a relação entre a dimensão clínica e a dimensão preventiva, bem como suas transformações a partir de sua fronteira e do que esse espaço fronteiriço expressa acerca do campo da saúde, seus movimentos de captura e de singularização.

Na mesma proporção em que estamos apontando exemplos e potencialidades desse modo de produzir conhecimento, podemos apontar alguns de seus desafios.

O primeiro deles está dado a partir da própria conjuntura atual das universidades e das agências de fomento à pesquisa. As linhas de força e de saber-poder presentes nessas instâncias são regidas ainda fortemente pelos ideais positivistas de produção de conhecimento, o que se constitui como um entrave para o desenvolvimento de parte das pesquisas qualitativas, entre elas as pesquisas cartográficas.

Com isso, não queremos opor as diferentes formas de produção de saber, valorizando um modo de pesquisa em detrimento de outro, ao contrário, entendemos que as pesquisas de cunho positivistas tiveram e têm, até hoje, grandes contribuições para as ciências modernas e para a produção da realidade; no entanto, uma vez enunciados seus limites é necessário que haja maior flexibilidade e abertura para a criação e desenvolvimento de novas formas de pesquisar, novas formas de ampliar a relação pesquisador-objeto de pesquisa.

Outro desafio do cartógrafo relaciona-se à construção da escrita cartográfica. Há que se configurar uma maneira de dizer, capaz de expressar a força da experiência. Um dos caminhos já apontados neste texto para a superação desse desafio é apostar nas "políticas da narratividade". Mas entendemos que ainda se faz necessária uma maior exploração sobre essa estratégia e maior desenvolvimento em relação às possibilidades da escrita e da apresentação das pesquisas que se pretendem cartográficas. Muitas vezes, a escrita formal e a linguagem discursiva mostram-se insuficientes, sendo necessária abertura para performances, vídeos, fotografias e outras formas de linguagem.

Outro desafio do cartógrafo é marcado pelo tempo. Ou seja, uma vez que visamos descrever processos, e não estados de coisa, o pesquisador se propõe a investigar elementos em relação e movimento. Ou seja, é necessário que se situe a pesquisa num espaço de tempo, numa espécie de recorte de um processo. Neste caso, o objeto pesquisado, quando apresentado, nos fornecerá uma teia de enunciados que já não diz mais do que é, mas do que foi no ato da pesquisa. Ao mesmo tempo em que entendemos isso como um desafio, nos perguntamos se em qualquer outra forma de pesquisa qualitativa é possível escapar disso. Talvez, aceitar isso de antemão, aceitar o desafio de pensar a transformação do saber e dos modos de vida possa ser uma diferença no modo de produção da pesquisa cartográfica.

Neste sentido, as pesquisas qualitativas em saúde podem contar com as contribuições da cartografia como método, o que, em última instância, faz da experiência de pesquisar uma experiência de transversalidade na produção de conhecimento.

Para Guattari (2004), sinteticamente, a transversalidade é o que promove uma abertura do coeficiente comunicacional dos sujeitos e dos grupos, dissolvendo as hierarquias e, portanto, oferecendo espaço para a emergência da diferença. Com esse conceito, Guattari prepara a definição do método cartográfico, na qual analisar é, ao mesmo tempo, descrever, intervir; é, também, criar efeitossubjetividade e acompanhar as linhas que compõem um determinado plano a ser pesquisado. Benevides e Passos (2005) apostam na transversalidade como o que causa a efetiva transformação das ações clínico-políticas no plano das políticas públicas e, por isso, acreditamos que as pesquisas nesse campo também podem fazer essa aposta. 


\section{Considerações finais}

A partir deste trabalho, buscamos explorar as fronteiras entre pesquisa qualitativa, a produção de conhecimento em saúde e a cartografia. Para isso, apresentamos um breve histórico da pesquisa qualitativa no sentido de demonstrar que a metodologia científica não se restringe apenas ao planejamento e execução de um trabalho científico, mas pode se constituir como um poderoso instrumento de análise crítica da produção de conhecimento.

Destacamos, mais uma vez, que a exploração da fronteira entre essas formas de abordagem para a produção de conhecimento não busca afirmar uma sobreposição entre métodos qualitativos e cartografia, visto que uma pesquisa qualitativa não é sempre cartográfica, nem uma pesquisa cartográfica é apenas qualitativa.

Buscamos analisar quando e de que forma a pesquisa qualitativa pode ser dita também cartográfica. Sinteticamente, entendemos que isso acontece quando uma pesquisa qualitativa se propõe a acompanhar processos de forma interventiva, quando essa intervenção produz um mundo de enunciados e visibilidades até então não exploradas. Uma pesquisa que faz ver e falar linhas de força e de subjetivação que acompanham o território existencial pesquisado. Questões como essa podem não ser exclusivas da cartografia, mas estão na centralidade de sua abordagem.

Depois da retomada desse contexto histórico das pesquisas, nos remetemos à produção de conhecimento no campo da saúde e procuramos estabelecer articulações entre as pesquisas qualitativas neste campo e a cartografia, defendendo que a preocupação do cartógrafo, no encontro com seu objeto de pesquisa, é a de acompanhar as linhas que se traçam, marcar os pontos de ruptura e de enrijecimento, analisar os cruzamentos dessas linhas diversas que funcionam ao mesmo tempo (Kastrup, Barros, 2009).

Como falamos de uma proposta relativamente nova - a de fazer da cartografia um método de pesquisa -, consideramos que foi importante elucidar as origens filosóficas do termo e apresentar os conceitos contemporâneos que o constituem. Neste caminho, pretendemos analisar suas potências e seus desafios. Quando um investigador tem um 'objeto' processual e quer dar vazão à política de suas formas e funcionamentos, ele pode se valer de um método de trabalho como esse, afinado com a processualidade daquilo que investiga (Farina, 2008).

As influências dessa corrente no campo das pesquisas na Saúde Coletiva brasileira têm mostrado importante crescimento, conforme apresentado ao longo do texto, e podem nos ajudar a intervir na complexidade do SUS e na ação dos sujeitos individuais e coletivos, em direção à afirmação de suas diferenças e construção de projetos comuns. Essa construção, para Deleuze e Guattari (1972), é conduzida pelo desejo, enquanto energia propulsora da ação cotidiana dos sujeitos nas suas dimensões coletivas e individuais.

As pesquisas cartográficas em saúde buscam valorizar uma política pública com diversas subjetivações possíveis no encontro clínico, onde se afirme a significação múltipla da diferença e se privilegie o uso de tecnologias que ampliem a liberdade e, por assim dizer, as linhas de subjetivação livres na produção de conhecimento e na produção de saúde.

Os processos de saúde-doença-intervenção, a subjetividade e a objetivação do cuidado estão em metamorfose. Metamorfoseiam-se os programas de saúde que os promovem, assim como os sujeitos que os operacionalizam.

Neste sentido, concluímos que a maior função e, ao mesmo tempo, o maior desafio do cartógrafo nas pesquisas em saúde é dar condições de visibilidade e dizibilidade ao que se passa individual e coletivamente nos processos de produção de saúde, de cuidado e de vida. Para isso, o devirpesquisador deve estar aberto para atravessar e ser atravessado pelo processo de pesquisar e de cuidar. 


\section{Colaboradores}

Os autores trabalharam juntos em todas as etapas de produção do manuscrito.

\section{Referências}

ALVAREZ, J.; PASSOS, E. Cartografar é habitar um território existencial. In: PASSOS, E.; KASTRUP, V.; ESCÓSSIA, L. (Orgs.). Pistas do método da cartografia: pesquisaintervenção e produção de subjetividade. Porto Alegre: Sulina, 2009. p.131-49.

BARROS, R.B. Grupo: a afirmação de um simulacro. Porto Alegre: Sulina, 2007

BECKER, H.S. et al. Boys in white: student culture in medicine school. Chicago: University of Chicago Press, 1961.

BENEVIDES, R.; PASSOS, E. A humanização como dimensão pública das políticas de saúde. Cad. Saude Coletiva, v.1, n.3, p.561-71, 2005.

CAMPOS, G.W.S. Um método para análise e co-gestão de coletivos. 2.ed. São Paulo: Hucitec, 2005.

CARVALHO, S.R.; FERIGATO, S.H.; BARROS, M.E.B. Conexões: Saúde Coletiva e políticas de subjetividade. São Paulo: Hucitec, 2009.

CECCIM, R.B.; FEUERWERKER, L.C.M. Mudança na graduação das profissões de saúde sob o eixo da integralidade. Cad. Saude Publica, v.20, n.5, p.1400-10, 2004.

DELEUZE, G. Que és un dispositivo? In: BALIBAR, E. et al. (Orgs.). Michel Foucault, filósofo. Barcelona: Gedisa, 1990. p.155-63.

DELEUZE, G.; GUATTARI, F. Mil Platôs 1. São Paulo: Ed. 34, 1995.

O anti-Édipo. Lisboa: Assírio e Alvim, 1972.

DENZIN, N.K.; LINCOLN, Y.S. Handbook of qualitative research. Thousand Oaks: Sage, 2005.

DO EIRADO, A. Sentido e experiência no âmbito da atividade cognitiva. Rev. Psicol. (UFF), v.17, n.2, p.35-43, 2005.

EICHELBERGER, M. Uma política de subjetivações possíveis no encontro clínico e sanitário: pesquisa cartográfica e territórios. Campinas, 2009. (mimeogr.).

ESCÓSSIA, L.; TEDESCO, S. O coletivo de forças como plano de experiência cartográfica. In: PASSOS, E.; KASTRUP, V.; ESCÓSSIA, L. (Orgs.). Pistas do método da cartografia: pesquisa-intervenção e produção de subjetividade. Porto Alegre: Sulina, 2009. p.92-108.

FARINA, C. Arte e formação: uma cartografia da experiência estética atual. In: REUNIÃO ANUAL DA ANPED, 31., 2008, Caxambu. Anais... Caxambu, 1998. p.1-16. Disponível em: <http://www.anped.org.br/reunioes/31ra/1trabalho/GE01-4014-Int.pdf >. Acesso em: 13 ago. 2011.

FONSECA, T.M.G. Cartografias da arteloucura: a insurgência de um outro espaço. In: FONSECA, T.M.G.; ENGELMAN, S.; PERRONE, C.M. (Orgs.). Rizomas da reforma psiquiátrica: a difícil reconciliação. Porto Alegre: Sulina, 2007. p.141-52.

FRANCO, T.B.; MAGALHÃES JÚNIOR, H. Integralidade na assistência à saúde: a organização das linhas do cuidado. In: MERHY, E.E. et al. (Orgs.). O trabalho em saúde: olhando e experienciando o SUS no cotidiano. São Paulo: Hucitec, 2003. p.125-34.

FRANCO, T.B.; MERHY, E.E. Mapas analíticos: una mirada sobre la organización y sus procesos de trabajo. Salud Colect., v.5, n.2, p.181-94, 2009.

FRANCO, T.B. et al. (Orgs.). A produção subjetiva do cuidado: cartografias da Estratégia Saúde da Família. São Paulo: Hucitec, 2009. 
GIL, A.C. et al. Por que fazer pesquisa qualitativa em saúde? Cad. Pesqu. Cienc. Saude, v.1, n.2, p.5-19, 2006.

GUATTARI, F. Psicanálise e transversalidade: ensaios de análise institucional. Trad. Adail Ubirajara Sobral e Maria Stela Gonçalves. Aparecida: Idéias \& Letras, 2004. p.7584. (Coleção Psicanálise Século I).

Espaço e poder: a criação de territórios na cidade. Espaço Debates, v.5, n.16, p.109-20, 1985.

KASTRUP, V. O funcionamento da atenção no trabalho do cartógrafo In: PASSOS, E.; KASTRUP, V.; ESCÓSSIA, L. (Orgs.). Pistas do método da cartografia: pesquisaintervenção e produção de subjetividade. Porto Alegre: Sulina, 2009. p.32-51.

O método da cartografia e os quatro níveis da pesquisa-intervenção. In: CASTRO, L.R.; CORREA, J.; BESSET, V.L. (Orgs.). Pesquisa-intervenção na infância e juventude. Rio de Janeiro: Nau, 2008. v.1. p.465-89.

A invenção de si e do mundo: uma introdução do tempo e do coletivo no estudo da cognição. Campinas: Papirus, 1999.

KASTRUP, V.; BARROS, R.B. Movimentos-funções do dispositivo na prática da cartografia. In: PASSOS, E.; KASTRUP, V.; ESCÓSSIA, L. (Orgs.). Pistas do método da cartografia: pesquisa-intervenção e produção de subjetividade. Porto Alegre: Sulina, 2009. p.76-91.

LOURAU, R. Implicação e sobreimplicação. In: ALTOÉ, S. (Org.). René Lourau: analista institucional em tempo integral. São Paulo: Hucitec, 2004. p.186-98.

MATURANA, R.H.; VARELA, F.G. A árvore do conhecimento: as bases biológicas do entendimento humano. São Paulo: Editorial Psy II, 1995.

MERHY, E.E. Saúde: a cartografia do trabalho vivo. São Paulo: Hucitec, 2002.

ORLANDI, E.P. Interpretações: autoria, leitura e efeitos do trabalho simbólico. Petrópolis: Vozes, 1996.

PACHECO, J.; CARVALHO, S.R. A vontade de conhecer o meio: a fronteira clínicaprevenção. In: CARVALHO, S.R.; FERIGATO, S.; BARROS, M.E. (Orgs.). Conexões: Saúde Coletiva e políticas de subjetividade. São Paulo: Hucitec, 2009. p.94-118.

PAIVA, A.C.S. Sujeito e laço social: a produção de subjetividade na genealogia de Michel Foucault. Rio de Janeiro: Relume Dumará, 2000.

PASSOS, E.; BARROS, R.B. A cartografia como método de pesquisa intervenção. In: PASSOS, E.; KASTRUP, V.; ESCÓSSIA, L. (Orgs.). Pistas do método da cartografia: pesquisa-intervenção e produção de subjetividade. Porto Alegre: Sulina, 2009a. p.17-31.

Por uma política da narratividade. In: PASSOS, E.; KASTRUP, V.; ESCÓSSIA, L. (Orgs.). Pistas do método da cartografia: pesquisa-intervenção e produção de subjetividade. Porto Alegre: Sulina, 2009b. p.150-71.

PASSOS, E.; DO EIRADO, A. Cartografia como dissolução do ponto de vista do observador. In: PASSOS, E.; KASTRUP, V.; ESCÓSSIA, L. (Orgs.). Pistas do método da cartografia: pesquisa-intervenção e produção de subjetividade. Porto Alegre: Sulina, 2009. p.109-30.

PASSOS, E.; KASTRUP, V.; ESCÓSSIA, L. (Orgs.). Pistas do método da cartografia: pesquisa-intervenção e produção de subjetividade. Porto Alegre: Sulina, 2009.

PIAGET, J. O nascimento da inteligência na criança. Rio de Janeiro: Zahar, 1978.

POZZANA, L.; KASTRUP, V. Cartografar é acompanhar processos. In: PASSOS, E.; KASTRUP, V.; ESCÓSSIA, L. (Orgs.). Pistas do método da cartografia: pesquisaintervenção e produção de subjetividade. Porto Alegre: Sulina, 2009. p.52-75. 
RICHARDSON, L. Novas práticas de escrita na pesquisa qualitativa. Sociol. Desporto, v.17, n.1, p.5-20, 2000.

RICHARDSON, L.; PIERRE, E. Writing: a method of inquiry. In: DENZIN, N.; LINCOLN, Y. (Eds.). Handbook of qualitative research. 3.ed. Thousand Oaks: Sage, 2005. p.959-78.

ROLNICK, S. Cartografia sentimental. Porto Alegre: Sulina, 2007.

SANTOS, M. O retorno do território. Obs. Soc. Am. Lat., v.6, n.16, p.251-61, 2005.

TEIXEIRA, R.R. Acolhimento num serviço de saúde entendido como uma rede de conversações. In: PINHEIRO, R.; MATTOS, R.A. (Orgs.). Construção da integralidade: cotidiano, saberes e práticas em saúde. Rio de Janeiro: IMS-UERJ-Abrasco, 2003. p.89-111.

Agenciamentos tecnossemiológicos e produção de subjetividade: contribuição para o debate sobre a trans-formação do sujeito na saúde. Cienc. Saude Colet., v.6, n.1, p.49-61, 2001.

TURATO, E.R. Métodos qualitativos e quantitativos na área da saúde: definições, diferenças e seus objetos de pesquisa. Rev. Saude Publica, v.39, n.3, p.507-14, 2005.

FERIGATO, S.H.; CARVALHO, S.R. Investigación cualitativa, cartografía y salud: conexiones. Interface - Comunic., Saude, Educ., v.15, n.38, p.663-75, jul./set. 2011.

Con este trabajo de revisión bibliográfica pretendemos explorar los límites entre la producción de conocimientos en salud, la investigación cualitativas y la cartografía. Empezamos con una breve retrospectiva sobre la construcción histórica de la investigación cualitativa en general, para después presentar la investigación cartográfica como posible método de investigación cualitativa en salud. Una vez presentados los aspectos conceptuales de este modo de producción de conocimiento, tratamos de identificar sus potencialidades y los desafíos para el desarrollo de la investigación en el ámbito de la Salud Colectiva.

Palabras clave: Cartografía. Investigación cualitativa. Salud. 